\title{
PEMBELAJARAN YOGA DALAM PEMBENTUKAN KARAKTER SISWA DI PASRAMAN SAMIAGA MATARAM
}

\author{
Windariyanti ${ }^{1}$, I Nyoman Wijana ${ }^{2}$, Ni Putu Listiawati ${ }^{3}$ \\ ${ }^{123}$ Institut Agama Hindu Negeri Gde Pudja Mataram \\ Coresponding author: Windariyanti \\ Email: ketutwindariyanti142@gmail.com
}

\begin{abstract}
Abstact
Pasraman is a Hindu education system which aims to give birth to the younger generation who is not only a candidate in religious knowledge, but also has a noble character. One of the learning held by most of the pasraman is yoga learning as an effort to raise awareness of health and form of students character. Referring to that background, the writer conducted a study related to yoga learning that focused on planning, implementing, evaluating, and characters formed through yoga learning at Pasraman Samiaga Mataram.

This research was conducted using qualitative methods with descriptive qualitative data analysis. Data obtained from observation, interview, documentation, and checking data validity carried out with credibility, transferability, dependability, and confirmability. This research supported by behavioristic theory, Burner learning theory and theory of learning connectionism.

This study shown that yoga learning planning carried out by instructor by determining the learning objectives, designing learning materials, and determine the learning schedule. In the implementation of yoga learning is done gradually and at each stage tugged the strengthening of the character for the students. As for the stages of yoga learning at Pasraman Samiaga Mataram includes preparation stage, appetite prayer, stretching, surya namaskara, asanas, acro yoga, relaxation, and prayer cover. The evaluation of yoga learning which is carried out includes evaluation of process and evaluation of results are overseeing the development of each student's ability, carry out assessment at each meeting, and held a yoga race in the pasraman. The characters formed through yoga learning at Pasraman Samiaga Mataram includes religious character, discipline character, the characters are responsible, character appreciate achievement, character of curiosity and independent character.
\end{abstract}

Keywords: yoga learning, forming character, planning, implementation, evaluation

\begin{abstract}
Abstrak
Pasraman adalah sistem pendidikan Hindu yang bertujuan untuk melahirkan generasi muda yang tidak hanya cakap dalam pengetahuan agama, akan tetapi juga memiliki karakter yang mulia. Salah satu pembelajaran yang diadakan oleh sebagian besar pasraman adalah pembelajaran yoga sebagai upaya untuk meningkatkan kesadaran akan kesehatan dan pembentukan karakter siswa. Mengacu pada latar belakang tersebut, maka dilakukanlah penelitian terkait pembelajaran yoga yang berfokus pada perencanaan, pelaksanaan, evaluasi dan karakter yang terbentuk pada siswa melalui pembelajaran yoga di Pasraman Samiaga Mataram.

Penelitian ini dilakukan dengan menggunakan metode kualitatif dengan analisis data secara deskriptif kualitatif. Data diperoleh melalui observasi, wawancara dan dokumentasi, serta dilakukan pengecekan keabsahan data yaitu kredibilitas, transferabilitas, dependabilitas, dan konfirmabilitas. Penelitian ini didukung dengan teori behavioristik, teori belajar Bruner dan teori belajar koneksionisme.
\end{abstract}


Hasil penelitian menunjukkan bahwa perencanaan pembelajaran yoga yang dilakukan oleh instruktur yaitu dengan menentukan tujuan pembelajaran, merancang materi pembelajaran, dan menentukan jadwal belajar. Dalam pelaksanaan pembelajaran yoga dilakukan secara bertahap dan pada setiap tahapan diselipkan penguatan-penguatan karakter bagi siswa. Adapun tahapan pembelajaran yoga di Pasraman Samiaga Mataram meliputi tahap persiapan, doa pembuka, peregangan, surya namaskara, asanas, acro yoga, relaksasi dan doa penutup. Evaluasi pembelajaran yoga yang dilaksanakan mencakup evaluasi proses dan evaluasi hasil yaitu mengawasi perkembangan kemampuan setiap siswa, melaksanakan penilaian pada setiap pertemuan, dan mengadakan lomba yoga intern pasraman. Karakter yang terbentuk melalui pembelajaran yoga di Pasraman Samiaga Mataram meliputi karakter religius, karakter disiplin, karakter bertanggung jawab, karakter menghargai prestasi, karakter rasa ingin tahu dan karakter mandiri.

Kata Kunci: Pembelajaran yoga, pembentukan karakter, perencanaan, pelaksanaan, evaluasi

\section{PENDAHULUAN}

Karakter merupakan aspek penting yang perlu diperhatikan dalam pendidikan. Pendidikan tidak hanya menyangkut kecerdasan dalam hal pengetahuan saja, tetapi juga tentang bagaimana pengetahuan tersebut dapat membuat seseorang menjadi pribadi yang berkarakter. Karena seperti yang kita ketahui, sudah banyak sekali bukti bahwa orang yang dikatakan memiliki intelektual tinggi melakukan tindakan-tindakan yang menyimpang dan tidak sesuai dengan karakter. Istilah karakter yang dimaksud disini adalah karakter yang baik dan bisa berjalan sejalan dengan tantangan dan perubahan zaman (Budiasih, 2018). Adapun kedepannya, Negara Indonesia tidak hanya membutuhkan generasi muda yang kaya intelektual, akan tetapi juga kaya akan karakter yang luhur.

Penyimpangan- penyimpangan yang terjadi pada kalangan generasi muda seperti narkoba, konsumsi minuman keras, seks bebas, tawuran dan kenakalan remaja lainnya semakin marak terjadi. Inilah wujud sifat, watak dan kehendak manusia yang apabila dibiarkan akan menimbulkan pertikaian dan perpecahan dalam masyarakat (Martiasari, 2019). Dalam mencegah terjadinya penyimpanganpenyimpangan tersebut, tentu saja tidak hanya menjadi tanggung jawab sekolah atau pendidikan formal saja. Akan tetapi juga memerlukan dukungan dari pendidikan keluarga (informal) dan masyarakat (nonformal). Salah satu pendidikan dalam masyarakat (non formal) khususnya yang berkembang di dalam masyarakat Hindu adalah pasraman. Pasraman adalah salah satu sistem pendidikan Hindu yang berperan penting dalam pembentukan karakter generasi muda.

Pembelajaran di dalam pasraman tidak hanya bertujuan untuk memberikan pengetahuan tentang pelajaran agama saja. Akan tetapi lebih kepada praktik yang berhubungan dengan keagamaan dan mengajak peserta didik di pasraman untuk mengembangkan bakat dan minat yang disenangi. Tujuan pembelajaran di pasraman juga sejalan dengan tujuan pendidikan nasional dalam UndangUndang Nomor 20 tahun 2003 yaitu untuk mengembangkan dan membentuk watak serta peradaban bangsa yang bermartabat dalam mencerdaskan kehidupan bangsa bertujuan untuk mengembangkan potensi peserta didik agar menjadi manusia yang beriman dan bertaqwa kepada Tuhan Yang Maha Esa, berakhlak mulia, sehat, berilmu, cakap kreatif, mandiri dan menjadi warga Negara yang demokratis serta bertanggung jawab.

Salah satu pembelajaran yang tergolong wajib diadakan dalam setiap pasraman adalah pembelajaran yoga. Hal ini dikarenakan latihan yoga dapat memberikan ketenangan pikiran, 
kesehatan, kesimbangan dalam pengontrolan emosi, mengatasi masalah dengan keadaan emosi yang positif, dan berbagai macam solusi dapat ditemukan untuk mengatasi permasalahan kehidupan (Gunarta, 2017). Yoga disamping sebagai sarana untuk menghubungkan diri dengan Tuhan, juga untuk mengasah keterampilan peserta didik dan meningkatkan kesadaran mereka untuk menjaga kesehatan. Tidak terkecuali untuk pasraman-pasraman yang ada di Provinsi Nusa Tenggara Barat khususnya di Pulau Lombok. Terdapat sekitar 21 pasraman yang berada di Kota Mataram dan beberapa pasraman yang tersebar di kabupaten lainnya.

Khususnya di Kota Mataram, salah satu pasraman yang aktif melaksanakan kegiatan yoga dan selalu berperan serta dalam setiap ajang perlombaan yoga adalah Pasraman Samiaga. Awalnya pengelola pasraman mengalami kesulitan dalam merekrut dan membina siswa pasraman, mengingat pengaruh lingkungan sekitar seperti sabung ayam dan minumminuman keras. Selain itu, minimnya pemahaman masyarakat tentang pentingnya mempelajari pengetahuan dan keterampilan keagamaan juga menjadi kendala. Kendala-kendala tersebut dapat dihadapi dan membawa Pasraman Samiaga menjadi salah satu pasraman di Kota Mataram yang telah mewakili tingkat provinsi ke kancah nasional dan mendapatkan juara dalam lomba yoga asanas. Dalam pasraman ini, pembelajaran yoga adalah pembelajaran wajib dan favorit bagi para siswa pasraman.

Berdasarkan observasi yang telah dilakukan sebelumnya, menunjukkan antusias siswa dalam mengikuti pembelajaran yoga. Berbeda halnya dengan pembelajaran yoga di pasramanpasraman lain yang sering terjadi pasang surut serta penurunan jumlah siswa. Hal ini tentu saja jarang terjadi di kalangan anakanak yang cenderung memiliki karakter cepat merasa bosan dengan pembelajaran yang berlangsung secara terus menerus. Sebab menurut informasi dari pengelola
Pasraman Samiaga, pembelajaran yoga tidak hanya dilaksanakan satu bulan sekali seperti pasraman lain, akan tetapi setiap minggu. Karakter yang ditunjukkan oleh siswa pasraman mengalami perubahan ke arah lebih baik setelah mengikuti pembelajaran di pasraman. Dari yang awalnya kurang disiplin menjadi disiplin, siswa yang tidak bisa melantunkan tri sandhya sudah bisa melaksanakan sembahyang rutin di rumah masingmasing.

Hal ini tentu saja menjadi ketertarikan bagi peneliti untuk mengetahui penerapan pembelajaran yoga yang dilaksanakan di Pasraman Samiaga. Selain untuk mengetahui pelaksanaan pembelajarannya, juga mengenai perencanaan dan evaluasi pembelajaran yoga dalam pembentukan karakter siswa. Hal ini nantinya dapat dijadikan acuan oleh pasraman lainnya tidak hanya dalam penerapan pembelajaran yoga, akan tetapi diharapkan pula untuk pembelajaran lainnya dalam pasraman. Berdasarkan fenomena tersebut diatas, maka permasalahan yang peneliti kaji adalah (1) Bagaimana perencanaan pembelajaran yoga dalam membentuk karakter siswa di

Pasraman Samiaga Mataram,

Bagaimana pelaksanaan pembelajaran yoga dalam membentuk karakter siswa di Pasraman Samiaga Mataram, Bagaimana evaluasi pembelajaran yoga dalam membentuk karakter siswa di Pasraman Samiaga Mataram, (4) Karakter apa sajakah yang dapat dibentuk pada siswa melalui pembelajaran yoga di Pasraman Samiaga Mataram.

\section{METODE}

Berdasarkan pada permasalahan dalam penelitian ini, maka peneliti menggunakan penelitian kualitatif, metode penelitian ini tidak menggunakan angka kalaupun ada angka itu hanya sebagai pelengkap saja. Penelitian ini terfokus pada kajian pembelajaran yoga dalam pembentukan karakter siswa di Pasraman Samiaga Mataram yang dilihat dari hasil 
observasi, wawancara, dokumentasi dan pencatatan. Dari data dan informasi yang peneliti peroleh, kemudian akan dianalisis agar diperoleh suatu penyimpulan yang menjadi hasil penelitian berupa saran atau rekomendasi baik untuk Pasraman Samiaga Mataram maupun pasramanpasraman lainnya di Pulau Lombok untuk dapat melaksanakan pembentukan karakter melalui pembelajaran yoga .

Adapun sumber data yang digunakan dalam penelitian ini yaitu data primer dan data sekunder. Dalam pelaksanaan penelitian, peneliti menggunakan tiga teknik pengumpulan data yaitu observasi non partisipan, wawancara tidak terstruktur dan dokumentasi. Selanjutnya data yang telah dikumpulkan dianalisis dengan proses reduksi data, kemudian penyajian data serta pada akhirnya dilakukan penarikan kesimpulan. Untuk mempermudah proses analisis data digunakan teori behavioristik, teori belajar Bruner dan teori belajar koneksionisme. Sedangkan untuk melakukan pengecekan keabsahan data secara kualitatif dilakukan uji credibilittas, transferability, dependability, dan confirmability.

\section{HASIL DAN PEMBAHASAN}

Perencanaan Pembelajaran Yoga dalam Pembentukan Karakter Siswa di Pasraman Samiaga Mataram

1) Menentukan Tujuan Pembelajaran

Tujuan sangat penting dalam menentukan arah atau sasaran yang ingin dicapai, sehingga apa yang dilaksanakan dapat sesuai dan mengarah pada tujuan tersebut. Tujuan yang hendak dicapai tentunya disesuaikan dengan perencanaan yang harus selaras, sesuai, sepadan dan cocok dengan situasi kondisi dimana pembelajaran dikembangkan (Suryapermana, 2017). Demikian halnya dalam pembelajaran yoga, pembelajaran ini direncanakan untuk mencapai tujuan dalam setiap pembelajaran termasuk pembelajaran yoga. Di Pasraman Samiaga Mataram pembelajaran yoga bertujuan untuk menciptakan siswa pasraman yang berkarakter serta sehat secara jasmani dan rohani. Karakter pada siswa ini akan terbentuk apabila diberikan sentuhan yang positif baik secara fisik, mental maupun spiritual, dan salah satu caranya adalah melalui latihan yoga ini (Rudiarta, 2020b).

Sejalan dengan teori behavioristik dalam Anwar (2017: 18-19), dimana poin penting dari teori ini ialah seseorang dianggap telah belajar sesuatu jika ia dapat menunjukkan perubahan tingkah lakunya. Di Pasraman Samiaga Mataram menjadikan perubahan karakter sebagai respons yang diharapkan. Perubahan karakter yang dimaksud tentunya perubahan kearah yang lebih baik.

\section{2) Merancang Materi Pembelajaran}

Materi yang diberikan bertujuan untuk memberikan pemahaman kepada siswa mengenai filosofi, manfaat, doa dan syarat-syarat sebelum melakukan latihan yoga. Yoga merupakan ajaran yang dapat memberikan kesehatan mental dan juga self healing bagi praktisi ketika dilakukan secara rutin (Rudiarta, 2021). Untuk mentransformasi hal tersebut, materi yang akan disampaikan dirancang agar tidak terlalu berat untuk dipahami oleh seluruh siswa pasraman yang berasal dari berbagai usia. Gerakan-gerakan yang nantinya akan dicontohkan, ditulis dan digambarkan secara sederhana agar mudah diingat. Catatan ini nantinya akan menjadi pegangan bagi insruktur yoga agar pembelajaran lebih terarah dan memiliki tahapan-tahapan yang jelas. Dalam merencanakan pembelajaran, guru yoga juga mempertimbangkan tentang tingkat pendidikan, usia siswa pasraman yang berbeda, kemampuan masing-masing siswa serta lama masa belajar di pasraman. Hal ini dikarenakan Guru merupakan salah satu unsur penting dalam perencanaan pembelajaran yang akan berimplikasi pada keberhasilan pembelajaran (Wiguna \& Dewi, 2020). 


\section{3) Menentukan Jadwal Belajar}

Di Pasraman Samiaga Mataram, setiap minggu melaksanakan pembelajaran yoga. Selain itu, untuk memaksimalkan latihan yoga terutama bagi yang memilih kelas peminatan yoga, dijadwalkan juga latihan pada hari sabtu sore ketika siswa lain sedang melaksanakan pembelajaran tari. Hal ini bertujuan untuk membiasakan siswa dalam melakukan yoga dan menjadikan yoga sebagai rutinitasnya. Penentuan jadwal belajar yoga berdasarkan pokok bahasan yang berbeda setiap minggu atau setiap kali pertemuan. Pada awal pertemuan akan diajarkan surya namaskara, minggu selanjutnya asanas kemudian acro yoga. Setelah semua pokok bahasan dipelajari atau dipraktikkan dan siswa dianggap sudah menguasai, maka pada minggu selanjutnya seluruh pokok bahasan digabung menjadi satu. Hal ini bertujuan untuk memfokuskan siswa dalam memahami setiap pokok bahasan.

\section{Pelaksanaan Pembelajaran Yoga dalam Pembentukan Karakter Siswa di Pasraman Samiaga Mataram}

1. Persiapan dan Tri Sandhya

Menurut hukum kesiapan dalam teori koneksionisme, hubungan antara stimulus dan respons akan mudah terbentuk manakala ada kesiapan dalam diri individu. Implikasi praktis dari hukum ini adalah keberhasilan belajar seseorang sangat bergantung dari ada atau tidak adanya kesiapan. Sebelum memulai pembelajaran yoga, diperlukan persiapan baik dari segi tempat latihan maupun kesiapan dari siswa. Persiapan dimulai dari membersihkan areal sekitar tempat yang akan digunakan untuk latihan. Hal ini juga dapat memupuk rasa kerjasama antar siswa pasraman dan meningkatkan rasa peduli lingkungan. Setelah persiapan tempat, selanjutnya sebelum pembelajaran yoga dimulai seluruh siswa melantunkan puja tri sandhya bersama. Hal ini bertujuan untuk memfokuskan pikiran seluruh siswa dan meningkatkan vibrasi positif di sekitar tempat belajar atau latihan. Menghadirkan vibrasi positif dalam latihan yoga merupakan wujud keinginan menghadirkan kembali nilai spiritualitas dalam kehidupan modern (Dayuh, 2016).

\section{Doa Pembuka}

Pada umumnya, pasramanpasraman yang ada di Pulau Lombok menggunakan doa pembuka sebelum pembelajaran yoga yang terdiri dari mantram gayatri, mantram guru dan maha mrtyun jaya. Berbeda halnya dengan Pasraman Samiaga yang menggunakan mantram Patanjali sebagai doa pembuka yang terdiri dari:

Bait I:

Yogena cittasya, padena vācām

Malam śarirasya ca vaidyakena

Yo'pākarot tam pravaraì muninaì

Patañjalim prāñalir ānato'smi.

Terjemahannya: Untuk memurnikan pikiran, perkataan dan badan, ia mempersembahkan yoga, tata Bahasa dan ilmu pengobatan, ia yang tersucikan dan mulia ijinkan hamba mendekati oh Mahayogi Patanjali (Tim Penyusun, 2016: 6-7).

Bait II:

ābāhu purușākāram

sankkacakrāsi dhārinam

sahasra śirasam śvetam

pranamāmi patañjalim

Terjemahannya: Ia yang berwujud ular kobra putih berkepala seribu dan berbadan manusia, bersenjatakan sankakala dan cakra terimalah sembah bhakti hamba oh Mahayogi Patanjali (Tim Penyusun, 2016: 7).

\section{Peregangan}

Merupakan tahapan awal dalam melakukan latihan yoga yang bertujuan untuk meregangkan persendian dan syaraf pada tubuh serta mencegah terjadinya cidera. Tahap peregangan ini meliputi peregangan pada kepala, bahu, lengan, siku, jari-jari dan pergelangan tangan, pinggang, pergelangan kaki dan jari-jari kaki. 


\section{Surya Namaskara}

Tim Penyusun (2016: 19) menyebutkan bahwa melakukan Surya Namaskara atau penghormatan kepada matahari, matahari adalah sumber kehidupan, memancarkan cahaya dimaknai sebagai pencerahan untuk melenyapkan kegelapan yang dikorelasikan dengan kebodohan. Adapun tahapan dalam surya namaskara terdiri dari 12 gerakan meliputi pranamasana (sikap berdoa), hasta uttanasana (sikap kedua lengan terangkat), padahastasana (sikap tangan sampai ke kaki), aswa sancalanasana (sikap menunggang kuda), parwatasana (sikap gunung), astangga namaskara (sikap penghormatan kepada 8 anggota badan), bhujanggasana (sikap kobra), parwatasana (sikap gunung), aswa sancalanasana (sikap menunggang kuda), padahastasana (sikap tangan sampai ke kaki), hasta uttanasana (sikap kedua lengan terangkat) dan pranamasana (sikap berdoa). Surya Namaskara secara spiritual merupakan bentuk pemujaan kepada dewa surya yang dapat memberikan sentuhan battin lebih mendalam dan nantinya bisa menumbuhkan rasa bersahabat (maitri) untuk berbagi kasih selama melakukan latihan (Rudiarta, 2020c)

\section{Asanas}

Pada tahapan asanas ini, disesuaikan dengan kemampuan siswa yang awalnya diberikan gerakan dasar terlebih dahulu. Bagi yang telah dianggap menguasai, maka akan dilanjutkan dengan gerakan-gerakan tingkat menengah hingga tinggi. Adapun beberapa asanas yang biasa diajarkan pada saat pembelajaran yoga di Pasraman Samiaga Mataram yang terdiri dari posisi duduk, setengah berdiri, berdiri, telungkup dan terlentang meliputi tadasana (sikap pohon palem), wirabadrasana (sikap prajurit), vrksasana (sikap pohon), naukasana (sikap perahu), cakrasana (sikap roda), purna bhujanggasana (sikap kobra), ustrasana (sikap unta), dhanurasana (sikap busur), trikonasana (sikap segitiga), paschimottanasana (sikap mencium lutut), sarwanggasana (sikap lilin), halasana (sikap bajak) dan purna siwanataraja (sikap tarian dewa siwa). Ketika melakukan berbagai pose asana ini, secara fisik postur asana nampak seperti statis dan selama melakukan asana terjadi sebuah kontraksi pada anatomi tubuh disertai berlangsun teknik pernapasan yang tepat dan bermanfaat bagi tubuh (Adnyani, 2020).

\section{$\underline{\text { 5. Kolaborasi (acro yoga) }}$}

Kolaborasi gerakan adalah gabungan dari beberapa gerakan yang saling melengkapi untuk menciptakan kombinasi yang indah. Biasanya latihan acro yoga diperuntukkan bagi siswa yang akan mengikuti perlombaan untuk melatih kemantapan dan kekuatan gerak.

Acro yoga memang dijadikan salah salah satu ajang promosi penyebaran ajaran yoga. Tidak dipungkiri Acro Yoga menjadi tren saat ini dikalangan selebriti Indonesia (Hemamalini, 2020). Sehingga kerapkali setiap latihan asana diakhiri dengan latihan acro.

\section{Relaksasi (Sawasana)}

Tahapan relaksasi ini adalah tahapan yang tepat untuk memberikan sugesti-sugesti positif kepada siswa. Sugesti tersebut berupa penanaman nilainilai karakter mulia akan coba diresapkan pada alam bawah sadar para siswa, sehingga nilai-nilai akhlak mulia tersebut akan masuk ke dalam rohani para siswa dan ke depannya setiap tingkah laku selalu dituntun untuk melakukan hal yang mengutamakan ajaran Dharma. Dengan relaksasi para siswa akan memperoleh ketenangan alami yang berimplikasi pada kemudahan sugesti positif masuk (Nurjannah, 2018).

\section{Doa Penutup}

Om Sarve Bhavantu Sukinah

Sarve Santu Niramayah

Sarve Badranih Pasyantu

Makascit dukha bag bhavet

Loka Samasta Sukino Bhawantu $3 X$ 


\section{Om Santih, Santih, Santih Om}

Artinya:

Semoga semua makhluk makmur dan berbahagia,

Semoga semua makhluk terbebas dari penyakit,

Semoga semua makhluk melihat peningkatan spiritual,

Semoga semua makhluk tidak menderita

Damai damai damai

\section{Evaluasi Pembelajaran Yoga dalam} Pembentukan Karakter Siswa di Pasraman Samiaga Mataram

Di Pasraman Samiaga Mataram, evaluasi yang dilaksanakan mencakup evaluasi hasil dan evaluasi proses. Instruktur yoga selalu mengevaluasi proses pembelajaran yang dijalankan dan selalu menilai siswa ketika sedang mengikuti pembelajaran. Dengan adanya evaluasi proses, maka memungkinkan untuk melakukan perbaikan selama proses masih berjalan sehingga hasil yang diperoleh lebih maksimal. Sedangkan evaluasi hasil juga selalu dilakukan untuk melihat sejauh mana hasil belajar siswa sekaligus memberikan penilaian untuk mereka. Dengan memberikan penilaian dan tanggapan atas hasil belajar siswa akan lebih termotivasi untuk meningkatkan atau mempertahankan hasil belajarnya.

Evaluasi pembelajaran yoga yang dilaksanakan di Pasraman Samiaga Mataram meliputi mengawasi perkembangan kemampuan setiap siswa, melaksanakan penilaian pada setiap pertemuan dan mengadakan lomba yoga intern pasraman. Melalui evaluasi yang dilakukan, diharapkan pembelajaran yoga yang dilakukan tidak menyimpang dari nilai-nilai pendidikan Hindu sebagaimana yang tertuang dalam susastra Hindu dan ajaran Tri Hita Karana, Tri Kaya Parsudha, serta ajaran Catur Paramita (Rudiarta, 2020a).

\section{Karakter yang Terbentuk Melalui Pembelajaran Yoga di Pasraman Samiaga Mataram}

Pembelajaran yoga yang

dilaksanakan di Pasraman Samiaga Mataram bertujuan untuk membawa perubahan karakter siswa ke arah yang lebih baik. Perubahan karakter pada siswa di Pasraman Samiaga Mataram telah terlihat yang mengartikan bahwa esensi belajar telah sesuai dengan teori behavioristik. Karakter yang terbentuk melalui pembelajaran yoga di Pasraman Samiaga Mataram yaitu (1) karakter religius atau nilai keagamaan yang dimiliki oleh siswa sejak belajar di Pasraman Samiaga Mataram mengalami perubahan ke arah yang lebih baik yang ditunjukkan dengan perubahan kebiasaan siswa menjadi rajin melaksanakan puja tri sandhya dan melantunkan doa sehari-hari; (2) karakter disiplin, dimana siswa Pasraman Samiaga Mataram dilatih untuk disiplin sejak awal mengikuti pasraman. Disiplin yang dimaksud meliputi disiplin waktu, disiplin berpakaian, disiplin berbicara, disiplin belajar dan disiplin lingkungan; (3) karakter bertanggung, dapat terlihat ketika siswa diberi kepercayaan untuk mewakili pasraman pada ajang perlombaan, siswa pasraman diminta untuk melatih yoga di sekolah dan pasraman lain agar belajar untuk menjadi instruktur di depan; (4) karakter menghargai prestasi, Pasraman Samiaga Mataram dikenal sebagai salah satu pasraman yang paling sering memperoleh prestasi dan juara terutama dalam bidang yoga. Akan tetapi hal ini tidak membuat siswa pasraman memandang enteng setiap perlombaan yang diikuti. Dalam setiap perlombaan, siswa pasraman memberikan usaha terbaik dan tetap merasa rendah diri ketika mendapatkan prestasi; (5) karakter rasa ingin tahu, dimana hampir seluruh siswa Pasraman Samiaga Mataram memiliki rasa ingin tahu yang besar terutama mengenai gerakan yoga yang belum siswa ketahui. Motivasi siswa untuk mengetahui lebih banyak gerakan yoga dapat terlihat dari 
antusias siswa ketika diajarkan gerakan baru oleh instruktur yoga; (6) karakter mandiri, ditunjukkan ketika guru pasraman tidak bisa datang tepat waktu, maka siswa mempunyai inisiatif sendiri secara mandiri membersihkan areal pasraman dan mempersiapkan sarana yang akan digunakan dalam pembelajaran. Karakter mandiri juga dibiasakan dengan menabung di pasraman agar uang jajan yang diberikan oleh orang tua dapat disisihkan. Karakter yang terbentuk ini sesuai dengan temuan Pramana (2020) yang menyatakan bahwa latihan yoga akan memberikan implikasi pada kesehatan dan kebugaran, kelenturan, dan kekuatan. Kesehatan dan kebugaran dimaksudkan sehat dan bugar secara pola pikir, sehingga dapat selalu bersikap penuh kesadaran. Kemudian kelenturan, menunjukkan keluwesan cara berpikir agak bersifat fleksibel dengan situasi kondisi, serta kekuatan menunjukkan kekuatan mental dalam menjalani berbagai aktivitas kehidupan sehari-hari.

\section{PENUTUP}

\section{Simpulan}

Berdasarkan hasil penelitian dan hasil analisis data yang telah peneliti laksanakan, maka dapat ditarik kesimpulan sebagai berikut:

1. Perencanaan pembelajaran yoga dalam pembentukan karakter siswa yang dilaksanakan di Pasraman Samiaga Mataram meliputi menentukan tujuan pembelajaran, merancang materi pembelajaran,dan menentukan jadwal belajar. Pada umumnya perencanaan pembelajaran yoga di Pasraman Samaiaga Mataram tidak dituangkan secara tertulis, akan tetapi memiliki persiapan yang dirancang sebelum akhirnya diterapkan dalam tahap pembelajaran.

2. Pelaksanaan pembelajaran yoga dalam pembentukan karakter siswa di Pasraman Samiaga Mataram dilaksanakan secara bertahap dan pada setiap tahapan diselipkan penguatan-penguatan karakter bagi siswa. Adapun tahapan pembelajaran yoga di Pasraman Samiaga Mataram meliputi tahap persiapan, doa pembuka, peregangan, surya namaskara, asanas, acro yoga, relaksasi dan doa penutup.

3. Evaluasi pembelajaran yoga dalam pembentukan karakter siswa di Pasraman Samiaga Mataram mencakup evaluasi proses dan evaluasi hasil. Evaluasi tersebut meliputi mengawasi perkembangan kemampuan setiap siswa, melaksanakan penilaian pada setiap pertemuan, dan mengadakan lomba yoga intern pasraman.

4. Karakter yang terbentuk melalui pembelajaran yoga di Pasraman Samiaga Mataram meliputi karakter religius, karakter disiplin, karakter bertanggung jawab, karakter menghargai prestasi, karakter rasa ingin tahu dan karakter mandiri.

\section{Saran}

Dari hasil penelitian dan pembahasan yang telah peneliti uraikan, dapat dituliskan beberapa saran sebagai berikut:

1. Terhadap peneliti lain diharapkan untuk lebih mengembangkan penelitian tentang pembelajaran yoga dalam pembentukan karakter siswa pada pasraman-pasraman non formal.

2. Bagi pengelola pasraman hendaknya penanaman nilai-nilai karakter senantiasa diberikan kepada siswa pasraman disamping juga memberikan keterampilan dan pengetahuan keagamaan.

3. Bagi guru pasraman hendaknya melaksanakan perencanaan yang matang sebelum melaksanakan proses pembelajaran dan nantinya akan mengevaluasi keberhasilan 
siswa dalam memahami dan mengaplikasikan nilai-nilai karakter dalam kehidupan sehari-hari.

\section{DAFTAR PUSTAKA}

Adnyani, N. M. (2020). Kerja Anatomi Tubuh dalam Yoga Asana. Jurnal Yoga Dan Kesehatan, 1(1), 38. https://doi.org/10.25078/jyk.v1i1.1 542

Anwar, Chairil. (2017). Teori-Teori Pendidikan Klasik Hingga Kontemporer. Yogyakarta: IRCiSod.

Budiasih, N. W. (2018). Membangun Karakter Bangsa Melalui Pendidikan Multikultur. Guna Widya: Jurnal Pendidikan Hindu, 5(2).

https://doi.org/10.25078/gw.v5i2.64 6

Dayuh, I. N. (2016). Pengetahuan Spiritual Yoga. Jurnal Penjaminan Mutu, 1(2), 79. https://doi.org/10.25078/jpm.v1i2.5 3

Gunarta, I. K. (2017). Implementasi Pembelajaran Yoga Dalam Meningkatkan Konsentrasi Belajar Di Sekolah Dasar Negeri 1 Sumerta. Jurnal Penjaminan Mutu, $3(2)$, 180. https://doi.org/10.25078/jpm.v3i2.1 98

Hemamalini, K. (2020). Kontestasi Figural dalam Industri Budaya Yoga. Jurnal Yoga Dan Kesehatan, 1(1), 48.

https://doi.org/10.25078/jyk.v1i1.1 543

Martiasari, A. (2019). Kajian Tentang Perilaku Kejahatan Dan Penyimpangan Seksual Dalam Sudut Pandang Sosiologis Dan Hukum Positif Indonesia. Yurispruden, 2(1), 103. https://doi.org/10.33474/yur.v2i1.9 58

Nurjannah, S. (2018). RELAKSASI
YOGA TERHADAP TEKANAN DARAH PASIEN HIPERTENSI. Journal of Holistic and Traditional Medicine, 3(02), 285-291.

Pramana, I. B. K. Y. (2020). PERAN INSTRUKTUR YOGA DALAM MENTRANSFORMASI

KESEHATAN DI LOMBOK YOGA CENTER KOTA MATARAM. MEDIA BINA ILMIAH, 14(9), 3171-3178.

Rudiarta, I. W. (2020a). Implementasi Pendidikan Berbasis Hindu Dalam Membangun Harmoni Di Era Disrupsi Sosial. Prosiding STHD Klaten Jawa Tengah, 1(1), 39-50. https://prosiding.sthd-

jateng.ac.id/index.php/psthd/article/ view/28

Rudiarta, I. W. (2020b). Implikasi Latihan Yoga Asana. Sinta 3, 23-33.

Rudiarta, I. W. (2020c). CATUR PARAMITA SEBAGAI PENDEKATAN LATIHAN YOGA ASANA DI STAHN GDE PUDJA MATARAM. MEDIA BINA ILMIAH, 14(11), 33453356.

Rudiarta, I. W. (2021). GENTA HREDAYA Volume 5 No 1 April 2021 YOGA SEBAGAI UPAYA MENCAPAI KESEHATAN MENTAL ( Kajian Yoga Sutra Patanjali ). 5(1), 57-66.

Suryapermana, N. (2017). Manajemen Perencanaan Pembelajaran. Tarbawi: Jurnal Keilmuan Manajemen Pendidikan, 3(02), 183. https://doi.org/10.32678/tarbawi.v3 i02.1788

Tim Penyusun. (2016). Modul 50 Jam Teacher Training Course Yoga Sanstha Institute (Tidak dipublikasikan). Klungkung: Ashram Gandhi Puri.

Wiguna, I. B. A. A., \& Dewi, K. A. T. R. (2020). Strategi Guru Dalam Peningkatan Mutu Pembelajaran Etika Hindu. Jurnal Penjaminan Mutu, 6(2), 210-220. 